Identidad, memoria y transculturación en la novela de

Sebastian Barry, On Canaan's side | 213

\title{
IDENTIDAD, MEMORIA Y TRANSCULTURACIÓN EN LA NOVELA DE SEBASTIAN BARRY, ON CANAAN'S SIDE
}

\author{
Melina Aixa Denise Vigari ${ }^{62}$
}

Resumen: El presente trabajo de investigación forma parte del proyecto 'Literatura irlandesa: estudios socio-críticos y traducción como diálogo intercultural' que se desarrolla en la Facultad de Ciencias Humanas, Universidad Nacional de La Pampa, Argentina, y aborda la novela de Sebastian Barry, On Canaan's Side (2011). El mismo analiza los conceptos de frontera, diáspora y desplazamiento forzado y la transformación que se suscita en los personajes a lo largo de la novela produciendo en ellos alienación y pérdida. Basada en los recuerdos de Lilly Dunne - el personaje principal- y a raíz del suicidio de su nieto, la novela reconstruye el sujeto diaspórico a través de narrativas en las cuales el pasado continúa en el presente, mediante la construcción de la memoria, proporcionando un vínculo entre generaciones e historias familiares. La novela no sólo presenta los relatos de una familia signada por la guerra sino que, también, remarca el hecho de que las experiencias traumáticas permiten comprender las vivencias de aquellos individuos que experimentan soledad y desarraigo. En este sentido, On Canaan's Side revela la reconstrucción de la identidad del personaje principal en medio de un proceso de transculturación. Siguiendo los postulados de Eyerman y Megill (2011) sobre identidad y transmisión de la memoria, se pretende demostrar cómo la escritura y las experiencias de vida se entrelazan para reconstruir la identidad compleja pero adaptable del personaje principal.

Palabras clave: Frontera; Diáspora; Memoria; Identidad;

Transculturación.

Abstract: The present research work is part of the project 'Irish Literature: socio-critical studies and translation as intercultural dialogue' that is developed in the Faculty of Human Sciences of the University of La Pampa, Argentina, and deals with Sebastian Barry's novel, On Canaan's Side (2011). This paper analyzes the concepts of frontier,

62 Professora auxiliar de cátedra do Departamento de Lenguas Extranjeras, Facultad de Ciencias Humanas, Universidad Nacional de la Pampa. 
214 | Melina Aixa Denise Vigari

diaspora and forced displacement and the transformation that arises in the characters throughout the novel producing in them alienation and loss. Based on the memories of Lilly Dunne - the main character - after her grandson's suicide, the novel reconstructs the diasporic subject through narratives in which the past continues in the present, by means of the construction of memory, providing a link between generations and family histories. The novel not only portrays the accounts of a family framed by wars, but also highlights the fact that traumatic experiences serve the purpose of presenting the plight of isolated individuals that have been ripped off everything they have accomplished. In this sense, On Canaan's Side also reveals the reconstruction of the main character's own identity in the course of adaptation to many new contexts (process of transculturation). Following Eyerman and Megill's (2011) tenets on identity and the transmission of memory, the aim is to demonstrate how writing and living intertwine to reconstruct the main character's complex but ever adjusting identity.

Key words: Border; Diaspora; Memory; Identity; Transculturation.

Cuando la identidad se vuelve incierta, el valor de la memoria aumenta (MEGILL, 2011, p. 194)

Según Eyerman (2011, p. 305), "la carga del pasado pesa sobre el presente. El pasado se hace presente mediante interacciones simbólicas, a través de la narración y el discurso, siendo la memoria un producto de ambos". En la novela de Sebastian Barry On Canaan's Side (2011), el personaje principal, Lilly Dunne, relata la historia subjetiva y retrospectiva de su vida de manera bastante caótica y desorientada, produciendo una clara yuxtaposición entre el pasado y el presente. De hecho, a largo de la obra literaria la narración es absolutamente dependiente de la memoria del narrador, transformándose esta en la fuerza fundamental detrás de la auto-comprensión y la conformación de la identidad. La narradora utiliza sus recuerdos no sólo para establecer una conexión entre el pasado y el presente sino también para comprender el mundo que la rodea. Mientras que la protagonista reconstruye su biografía a través de sus memorias, dicha introspección se convierte en la base de su identidad. En palabras de Sarup (1996), la identidad no está solamente influenciada por eventos o acciones y sus consecuencias en el pasado sino también por cómo esos

${ }^{63}$ Todas las traducciones de citas son de mi autoría. 
Identidad, memoria y transculturación en la novela de Sebastian Barry, On Canaan's side | 215

eventos o acciones se interpretan retrospectivamente. Cada individuo construye y reconstruye su propia identidad al mismo tiempo que cuenta su historia de vida. De esta manera, a medida que Lilly Dunne recuerda su pasado, se esfuerza por estructurarlo y organizarlo a través de la narración y la memoria, con el propósito de identificar patrones y consistencias que le concedan a su vida un sentido de identidad.

La reconstrucción de la identidad del personaje-narrador principal también implica un proceso de auto-adaptación a nuevos contextos sociales, una transición que conlleva la ruptura y/o pérdida de lazos comunitarios y familiares, además de la problemática que supone la integración a una nueva cultura. Siguiendo los postulados de Butler (2011, p. 189), la palabra "diáspora" se define como la dispersión de grupos étnicos o religiosos, que han abandonado su lugar de procedencia originaria por diversas causas (conflictos bélicos, persecuciones políticas y religiosas, la búsqueda de mejores oportunidades), quienes se encuentran repartidos por el mundo (cabe destacar que muchos de ellos no cuentan con la posibilidad de regresar a su tierra natal). El concepto previamente definido permite establecer una fuerte conexión con las nociones de anhelo, exilio y desplazamiento forzado. De hecho, a lo largo de la novela, Lily Dunne es retratada como un sujeto diaspórico, un individuo que viaja a través de diversos niveles en los dominios culturales y sociales con el fin de crear una nueva identidad. Un sujeto diaspórico que, a su vez, adquiere dimensiones simbólicas en un proceso de transculturación, donde la historia individual y la historia colectiva retroalimentan la construcción de la identidad del personaje principal. Cabe destacar que el inmigrante- la persona que llega a un país diferente al propio-experimenta una serie de cambios a nivel no sólo individual sino social y cultural que van a influir en su adaptación psicosocial a la sociedad receptora, e incluso en su readaptación a la sociedad de origen, en caso de que pretenda retornar a su patria. En consecuencia, la migración geográfica experimentada por la protagonista, como sujeto diaspórico en los Estados Unidos, implica la construcción y negociación de su propia identidad dentro de diversos planos socio-culturales (acoplarse a nuevas culturas, costumbres, nuevos significados y entendimientos sociales diversos). Según Sarup (1996) la identidad, la esencia del sujeto, se forma y modifica en el diálogo continuo con el mundo cultural que lo rodea. Para Lilly, Estados Unidos simboliza "la tierra prometida" (Cannan), el lugar donde ella logra arraigarse, encontrando seguridad y refugio, mientras que Irlanda, su tierra de origen (homeland), representa sus memorias y 
recuerdos. En este sentido, se puede argumentar que el personaje principal experimenta un proceso de transculturación, ya que adopta y recibe las formas culturales de Estados Unidos sustituyendo parcialmente las propias.

En el libro Memoria, Guerra y Trauma, Hunt (2010, p. 161) remarca que "una de las formas más usuales que utilizan las personas para lidiar con sus recuerdos traumáticos es escribirlos como si fueran parte de una historia; esto, para algunos, es una manera efectiva de lidiar con dichos recuerdos". (1) Esta idea es palpable en la novela de Barry, donde la narradora experimenta una creciente conciencia de los efectos desencadenados por las experiencias traumáticas en su vida. Este tipo de narrativas ilumina los aspectos personales y públicos del trauma revelando la relación que se establece entre memoria e identidad dentro del complejo entretejido de los asuntos sociales y psicológicos. El trauma y la escritura no sirven simplemente como registros del pasado sino que, precisamente, registran la fuerza de una experiencia que no solo exige conciencia histórica sino también la recolección de recuerdos.

\section{Reconstrucción de los sujetos diaspóricos a través de la escritura}

Yo ya era una prisionera en el asilo abierto del mundo (BARRY, 2011, p. 71)

A lo largo de la historia aquellos grupos humanos que fueron desplazados de manera espontánea o inducida de su tierra de origen a un espacio lejano han compartido un mismo anhelo, encontrar no solo progreso material sino tranquilidad espiritual. Estos desplazamientos con frecuencia tienen un efecto desestabilizador en los sujetos migrantes, provocando una sensación de desarraigo de la cultura precedente y un profundo sentimiento de exilio. El sujeto diaspórico suele surgir a partir de eventos traumáticos, por ejemplo la dispersión forzosa, que no pueden ser remediados mediante procesos externos de asimilación y que, a su vez, dan forma a todos aquellos elementos necesarios que conforman la memoria colectiva. En este sentido, la novela de Barry aborda la problemática de la construcción/ producción de la subjetividad en el cruce de fronteras (desplazamiento espacial) y tradiciones. Lilly Dunne encarna la representación del sujeto diaspórico; ella se comporta como una inmigrante irlandesa bajo los ojos de la sociedad estadounidense pero su vez se percibe a sí misma como una exiliada hasta que, luego del suicidio de su querido nieto Bill, decide comenzar a escribir sus 
Identidad, memoria y transculturación en la novela de Sebastian Barry, On Canaan's side | 217

memorias. El hecho de plasmar en papel su pasado y su presente ayuda a la protagonista de la novela a tomar conciencia de que no puede dejar atrás sus orígenes, aunque así lo deseara, y le permite comprender que el impacto de la diáspora se camufla mientras que reconstruye su identidad, desarrollando un diálogo complejo entre su pasado diaspórico y la adaptación al presente.

Grecia, Estados Unidos, Arabia, Irlanda. Países de origen. Ningún lugar del mundo es la patria. La ternera regresa a donde obtuvo la leche. Ningún lugar del mundo es extranjero. En todas partes existe una patria para alguien y, por lo tanto, para todos nosotros (BARRY, 2011, p. 57).

El trauma y la reconstrucción de la identidad conllevan la incorporación de la escritura, como explica Eyerman (2011, p. 305) "lo que el pasado significa es relatado, entendido, interpretado y transmitido a través del lenguaje y el diálogo. Estos diálogos se enmarcan como historias, narrativas, que estructuran su forma de ser contadas e influyen en su recepción”. A pesar de que la protagonista es reacia a escribir, se esfuerza por crear una historia que le permita recrear su pasado.

Nada sobre la tierra me hubiera llevado a escribir. Odio escribir, odio los bolígrafos y el papel y todo ese alboroto. Lo he hecho bastante bien sin la escritura, creo. Oh, me estoy mintiendo a mí misma. He temido escribir (BARRY, 2011, p. 9).

Desarraigo, añoranza, adaptación, inserción e integración, conceptos que permiten comprender las experiencias de la narradora como sujeto diaspórico afectando directamente el desarrollo de su subjetividad y permitiendo determinar la existencia de una identidad étnica y una identidad diaspórica. El hecho de atravesar fronteras físicas y simbólicas implicó para Lilly estar contacto con otras culturas y esto causó cambios en su actitud que le impidieron volver a sus antiguos espacios de identidad. De esta manera, siguiendo a Butler (2011), Lilly Dunne presenta una identidad cultural que no es fija, se encuentra en un movimiento permanente de construcción y reconstrucción, ya que se conforma de múltiples identidades en su seno, que la caracterizan por su 
218 | Melina Aixa Denise Vigari

profunda trasformación permanente como consecuencia de la presencia de un otro intrínseco.

\section{Construcción de memoria e identidad}

Podemos ser inmunes a la fiebre tifoidea, el tétanos, la varicela, la difteria, pero nunca a la memoria. No hay inoculación contra eso.

(BARRY, 2011, p. 83)

La memoria autobiográfica no solo abarca los recuerdos de eventos personales específicos, sino que también juega un rol preponderante en la formulación del sentido del yo. Dado que la identidad puede analizarse como una historia interna y evolutiva del yo, la construcción y negociación de la misma implica la relación presente-pasado y su reconciliación. Según Sarup (1994, p. 93) "la identidad puede ser desplazada; puede ser híbrida o múltiple. Además, puede constituirse a través de la comunidad: familia, región, el Estado Nacional”. A lo largo de la novela, Lilly Dunne reconstruye su propia historia de vida a través del proceso narrativo. De hecho, su libro autobiográfico explora y analiza el yo como un producto de la historia y de la clase social, al mismo momento que retoma conceptos psicoanalíticos de la subjetividad que pueden brindar una perspectiva más clara sobre la construcción de su propia identidad.

Me desperté una y otra vez, sobresaltada, sin saber si era joven o vieja, si estaba en Estados Unidos o en Irlanda. Eso es lo que pasa cuando se rastrilla sobre el carbón viejo. Dragando el pasado. Sin embargo, confesaré que hay un cierto placer en esto. Rasguño la mesa de formica, pasando las páginas de este libro de relatos con mi lápiz. Parece que veo todo y a todos mientras escribo. De alguna manera extraña puedo saludar a mi padre otra vez. Me gustaría decirle, Papá, no sé dónde estás enterrado, lo siento mucho (BARRY, 2011, p. 41).

A una edad muy temprana Lilly, hija de un policía leal a la Corona Inglesa, se convirtió en migrante, una persona que cruzó la frontera, esa línea divisoria o borde que, según Alzaldúa (1987, p. 3), está en un constante estado de transición y permite definir y diferenciar los lugares seguros de los inseguros. Es así como junto a Tadg Bere, su amado novio, 
Identidad, memoria y transculturación en la novela de Sebastian Barry, On Canaan's side | 219

escapan de Irlanda perseguidos por los Black and Tans (el Ejército Republicano Irlandés), en busca de un nuevo comienzo, una nueva vida. En este sentido, la frontera simboliza un lugar de negociación y de congregación de subjetividades marginales y alternativas. A partir de ese momento, Lilly tiene que lidiar no solo con el dolor de la separación sino con la sensación de desarraigo, de no pertenecer. En consecuencia, la escritura y el recuerdo testimonial le permiten reflexionar sobre sus orígenes y la importancia de las nociones de familia y hogar. En palabras de Megill (2011, p. 195), "la memoria está orientada hacia el sujeto y se focaliza en un pasado real o imaginario solo porque ese pasado se percibe como crucial para dicho sujeto". La recolección de eventos pasados en la vida de Lilly está estrechamente relacionada con las inseguridades acerca de su identidad actual. Para ella, la memoria es una imagen del pasado construida por la subjetividad en el presente.

\section{Trauma, memoria y relato}

Pierdes un hijo, un hermano, lo que sea que sea, y mueres a consecuencia de eso, asi que estás caminando, respirando y pensando, pero no estás vivo. (BARRY, 2011, p. 30)

Las narrativas del trauma, narraciones ficticias que ayudan a acceder a las experiencias traumáticas, pretenden dilucidar los aspectos personales y públicos del trauma. De hecho, los recuerdos traumáticos y sus consecuencias deben ser entendidos en términos de "ausencia"- la ausencia de algo que no llegó a ubicarse en tiempo o espacio. Como se describe en la novela, el trauma requiere la integración de la escritura, tanto por el bien del testimonio como por el bien de la cura. Es así como la transformación del evento traumático en memoria narrativa permite que la historia se verbalice e integre al conocimiento general del pasado. Freyd (1998, p. 170) plantea que la escritura autobiográfica de las mujeres clarifica las formas en las que una escritora/ víctima puede crear "una interpretación episódica e integración de recuerdos sensoriales y afectivos previamente dislocados" (1). A lo largo de la novela, el personaje principal intenta sobrevivir mediante la creación de una historia que le permita, por un lado, afrontar la pérdida y el duelo que conlleva la muerte de un ser querido y, por otro lado, lograr un sentido de continuidad personal reconsiderando su identidad. Cabe destacar que luego del suicidio de Bill, 
Lilly siente que su historia personal está incompleta, dolorosamente fragmentada y desorganizada, situación que impide una proyección a futuro.

No sé que soy, supongo que como cualquier persona afligida, tengo el corazón roto, pero aun así, en el centro de todo eso, en el corazón de las cosas, más allá de su alcance, puedo escuchar mi amor Bill que aún permanece, como el calor en el baño María (BARRY, 2011, p. 29).

La narración de los eventos traumáticos que marcaron su vida en el pasado y en el presente satisface la necesidad de orden y coherencia, ya que la misma proporciona continuidad temporal a su identidad. Esto significa que a través del desarrollo la protagonista logra recuperar la completud perdida.

Estoy insistiendo en cosas que amo, incluso una medida de tragedia está bordada en todo, si sigues el hilo lo suficiente.

(BARRY, 2011, p. 28)

La narrativa de Lilly incluye historias de asesinatos (Tagd Bere es perseguido y masacrado por los Black and Tans en Estados Unidos), guerras (Primera y Segunda Guerra Mundial, Guerra de Vietnam, Guerra del Golfo), expulsiones forzadas de la tierra natal y el suicidio de una amiga, eventos traumáticos que resultan en lesiones físicas y emocionales que no pueden asumirse con los esquemas cognitivos y emocionales habituales de la persona. De más está decir que en el centro de la narrativa, Lilly experimenta una oscilación entre una crisis de muerte, causada por el suicidio de su nieto soldado, y la crisis correlativa de la vida. De esta manera, la única manera que encuentra el personaje principal para poder lidiar con su dolor es a través de las páginas de su diario, narrado en el trascurso de diecisiete días. Como resultado, la novela gira en torno a una experiencia central de trauma que repercute en la cronología diegética y el testimonio post-traumático de Lilly. Si bien Barry no ahonda en los detalles de los acontecimientos históricos, el recorrido por la vida de la protagonista permite comprender las consecuencias de las guerras y las sociedades estremecidas por las mismas, trasformando a los sujetos en víctimas silenciosas que no causan los 
Identidad, memoria y transculturación en la novela de Sebastian Barry, On Canaan's side | 221 eventos pero los sufren. Como sugiere Caruth (1996, p. 8), una narrativa del trauma puede analizarse "no como la historia del individuo en relación con los eventos de su propio pasado, sino como la historia de la manera en que el propio trauma está atado con el trauma de otro".

Estoy tan aterrada por el dolor que no encuentro consuelo en nada. Llevo en mi cráneo una especie de esfera fundida en lugar de un cerebro, y estoy ardiendo allí, con horror y miseria (BARRY, 2011, p. 4).

Siguiendo los postulados de Alexander (2011, p. 307), se podría aseverar que la narrativa desarrollada por el personaje principal expone una secuencia de sucesos horrendos, situaciones traumáticas, que de una manera $u$ otra han dejado marcas indelebles, signando sus recuerdos para siempre, cambiando su identidad futura de una manera irrevocable.

\section{Conclusión}

La pena al principio se apoderó de nosotros, y luego se filtró en las sillas, y finalmente en las paredes y se filtró en el concreto. Yo estaré atada a ella, todavía está allí, si hubiera alguien con el corazón para sentirla, alguien allí que hubiera conocido a Willie, un nombre perdido en la historia del mundo (BARRY, 2011, p. 32)

La quinta novela de Sebastian Barry, On Canaan's Side (2011), comienza con una pregunta: “¿Cuál es el sonido de un corazón roto de ochenta y nueve años?”. Estas palabras reflejan una conciencia creciente de los efectos de la desesperación y opresión en la psique de un individuo como resultado de las experiencias traumáticas producidas, por un lado, por las secuelas de la guerra y, por otro, por las consecuencias del desplazamiento forzado. No cabe duda que el exilio, la soledad y el desarraigo trasforman al individuo migrante en un sujeto diaspórico, un ser incompleto, fragmentado, ya que no posee una identidad única y estable, sino múltiples identidades, muchas veces contradictorias entre sí (Germani, Obert, 2012). El personaje principal de la novela, Lilly Dunne, forma y transforma su identidad en relación a los sistemas culturales que 
la rodean, buscando construir una historia reconfortante que le permita identificarse y alcanzar la estabilidad emocional perdida.

Las narrativas del trauma se han transformado en una representación testimonial que permite iluminar los aspectos personales y públicos del trauma, dilucidando la relación existente entre memoria y narración. En consecuencia, dichas narrativas plantean cuestiones importantes respecto a la escritura y lectura del trauma y su conexión con la memoria, posicionando a los lectores frente a dilemas éticos, análogos a los que enfrenta la protagonista en la novela. La identidad se convierte en un lugar de compromiso así como de incertidumbre, mientras que la memoria es analizada como un discurso privilegiado que clama autenticidad y verdad. En este sentido, la novela presenta un narrador cuya identidad débil o amenazada parece ser una característica común en la unión de evocaciones de la memoria con el recuerdo de acontecimientos históricos profundamente preocupantes y dolorosos. Tal y como señala Megill (2011, p. 194), "la característica común que sustenta la mayoría de las manifestaciones contemporáneas de la locura o manía por la memoria parece ser la inseguridad sobre la identidad". En On Cannan's Side, el pasado está influenciado por los recuerdos de la infancia y la adolescencia de la protagonista, relatos situados en su Irlanda natal, mientras que el presente, turbulento y contradictorio, permite y promueve la reinterpretación de dichos sucesos. Lilly Dunne experimenta una necesidad desesperada por descubrir quién es realmente y, a la vez, se encuentra en una batalla constante entre el problema de la memoria, la fidelidad de los eventos vividos, el perdón, la culpa y la reconciliación con un pasado traumático. Tal y como señala Megill (2011, p. 194) "Cuando la identidad se vuelve incierta, el valor de la memoria aumenta”, en consecuencia la construcción de la identidad, híbrida, del personaje principal está fuertemente ligada a la reconstrucción de la memoria no solo individual, sino colectiva. El relato le permite a Lilly Dunne recordar el pasado, resignificar el presente y construir el futuro.

\section{BIBLIOGRAFÍA}

ALEXANDER, J. From Toward a Cultural Theory of Trauma. The Collective Memory Reader. Oxford University Press, 2011.

ANZALDUA, G. Borderlands: The New Mestiza - La Frontera. San

Francisco: Aunt Lute Books Company, 1987.

BARRY, S. On Canaan's Side. London: Faber and Faber Limited, 2011. 
Identidad, memoria y transculturación en la novela de Sebastian Barry, On Canaan's side | 223

BUTLER, K. Diaspora: A journal of Transnational Studies. University of Toronto Press, 2001.

CARUTH, C. Unclaimed. Experience. Trauma, Narrative, and History. The Johns Hopkins University Press Ltd., 1996.

EYERMAN, R. From The Past in the Present: Culture and the Transmission of Memory. The Collective Memory Reader. Oxford University Press, 2011.

FREYD, J.J Betrayal Trauma. The Logic of Forgetting Childhood Abuse. Harvard University Press, 1998.

GERMANI, M., OBERT, G. Configuración de identidades diaspóricas en cuentos irlandeses contemporáneos. Anuario Facultad Ciencias Humanas, UNLPam. VOL 10 No 1 - 2012.

HUNT, C. Memory, War and Trauma. Cambridge University, 2010.

MEGILL, A. From History, Memory, Identity. The Collective Memory Reader. Oxford University Press, 2011.

ROBERTSON, G. Travellers 'Tales: Narratives of home and displacement. London: Routledge, 1994.

SARUP, M. Home and Identity. In G. Robertson et al. (eds.): Travellers 'Tales: Narratives of home and displacement (pp.93-104). London: Routledge, 1994.

SARUP, M. Identity, culture, and the postmodern world. Edinburgh University Press, 1996.

Recebido em: 29/01/2018

Aceito em: 03/03/2018 